\title{
Does Lack of Resources within the Family Starting Point to Social Exclusion for Persons with Brain Cancer?
}

Sir,

Medical and psychiatric social workers (MPSW) play a crucial role in multidisciplinary health-care team and render services in a health-care setup in particular neurosurgical and neuro-oncology setup.$^{[1]}$ The MPSWs involve in psychosocial need assessment, care plan, and implementation of psychosocial interventions for the needy, i.e., persons with medical illness and their family members. The psychosocial interventions includes such as pre-admission counselling, psychotherapeutic interventions, behaviour modification, psycho-education, rendering help in social welfare benefits, rehabilitation services, pre-discharge counselling, follow-up and referral services.

MPSWs also keenly involved in doing home visits in the cases of abandoned and unknown cases to trace out the family members. The frequency of abandoned cases with medical illness has been increasing. Recently, our MPSWs team did a home visit of an abandoned person who has been suffering from brain cancer for the last 10 years. Armed with the names and address that were given by the patient, the MPSWs team was able to trace out the family residency and family members with the help of local volunteers and police personnel. MPSWs team found that the patient was abandoned and excluded from the family because of his chronic medical illness, behavioral problems, and social stigma associated with the illness. Adding to that, a lack of knowledge and family resources, they did not ready to take the patient home. Thus, left the patient alone in the hospital and departed to home. This dimension is important, yet over looked by Health Care Professionals including MPSWs when rehabilitation is planned for persons with chronic illness.

The caregiver burden is highly found among caregivers and family members in the palliative care..$^{[2]}$ The family resources such as family acceptance, existing living environment, family dynamics, knowledge on illness, caregiving roles and responsibilities, crisis and behavior management, coping abilities, supervision on drug adherence, day-to-day medical care, financial constraints, emergency medical care, social support, caregiver supportive groups, respite care, ways of social stigma, and feasibility for arranging the employment facilities for the patient need to be assessed before rehabilitation and reintegration at home. If found in adequate, the intensive psychosocial need assessment needs to be done and provides appropriate biopsychosocial interventions to the patient, family members, and caregivers for the successful rehabilitation. In addition, connecting with local health-care workers, nongovernmental organizations, and palliative care teams 
which are working for the well-being of chronic ill people, and their caregivers is also essential for the long-term care.

The other strategies such as periodically creating awareness programs on brain cancer in the community, conducting recreational programs, and continuing education on illness will increase realistic hope for caregivers and family members, which helps them to look after the brain cancer survivors at home well. Thus, we conclude that social exclusion for persons with brain cancer starts from within the family due to a lack of knowledge and above said resources. The MPSWs should focus more onto assess the available family resources, strengths, and utilize the same at the maximum to the family reintegration of abandoned than looking for institutionalization. ${ }^{[3,4]}$ Otherwise, it creates burden on family members, caregivers, health-care professionals, and even to the society.

\section{Financial support and sponsorship}

Nil.

\section{Conflicts of interest}

There are no conflicts of interest.

Birudu Raju, Suresh Lukose, N. Krishna Reddy Department of Psychiatric Social Work, National Institute of Mental Health and Neuro Sciences, Bengaluru, Karnataka, India

Address for correspondence: Dr. Birudu Raju, Department of Psychiatric Social Work, Neurosurgery Unit, National Institute of Mental Health and Neuro Sciences,

Bengaluru, Karnataka, India.

E-mail: birudurajupsy@gmail.com

\section{REFERENCES}

1. Shrivastava SR, Shrivastava PS, Ramasamy J. Medical social worker: Strengthening linkages between the hospital and the community. Int J Health Syst Disaster Manag 2014;2:130.

2. Khalili Y. Ongoing transitions: the impact of a malignant brain tumour on patient and family. Axone 2007;28:5-13.

3. Murthy RS. Caregiving and caregivers: Challenges and opportunities in India. Indian J Soc Psychiatry 2016;32:10.

4. Chadda RK. Caring for the family caregivers of persons with mental illness. Indian J Psychiatry 2014;56:221-7.

This is an open access article distributed under the terms of the Creative Commons Attribution-NonCommercial-ShareAlike 3.0 License, which allows others to remix, tweak, and build upon the work non-commercially, as long as the author is credited and the new creations are licensed under the identical terms.

\begin{tabular}{|l|l|}
\hline \multicolumn{2}{|c|}{ Access this article online } \\
\hline Quick Response Code: & Website: \\
\hline & www.ruralneuropractice.com \\
& \\
& \\
\end{tabular}

How to cite this article: Raju B, Lukose S, Reddy NK. Does lack of resources within the family starting point to social exclusion for persons with brain cancer?. J Neurosci Rural Pract 2016;7:S125-6. 